\title{
ERGONOMIC DESIGN RECOMMENDATIONS BASED ON AN ACTUAL CHAINSAW DESIGN
}

\author{
J. Kaljun ${ }^{1 *} \&$ B. Dolšak ${ }^{2}$ \\ Faculty for Mechanical Engineering \\ University of Maribor, Slovenia \\ 1 jasmin.kaljun@uni-mb.si, ${ }^{2}$ dolsak@uni-mb.si
}

\begin{abstract}
ABST RACT
To develop high quality products, a designer has to consider various influential factors, one of which is ergonomics. And to fashion a specific product for the user, a designer needs expert knowledge of the user's requirements. However, expert knowledge can also be accessed through an intelligent advisory system for ergonomic design support. The effectiveness of such an expert system depends mainly on the quality of the knowledge base and on the appropriateness of the system's inference engine. Data for the system's knowledge base can be collected in different ways. One approach is to study relevant projects to collect appropriate ergonomic solutions; another is to recognise bottlenecks in ergonomic design. This paper presents a case study of the design of an actual chainsaw with emphasis on ergonomic design solutions - that can be transformed into ergonomic design recommendations. At the end of the paper, an application of one of the derived recommendations within the knowledge base of the intelligent advisory system is presented.
\end{abstract}

\section{OPSOMMING}

By die ontwerp van gehaltegoedere moet aandag gegee word aan verskeie faktore soos die Ergonomie. Die produkontwerper moet deeglike kennis dra van die verbruikersbehoeftes. Daarbenewens moet hy liefs ook gebruik maak van 'n intelligente sisteem vir ontwerphulp. Die navorsing is toegespits op datasteun vir 'n kettingsaagontwerp en toon hoe die intelligente sisteem betekenisvolle ondersteuning verleen.

\footnotetext{
${ }^{1}$ The author was enrolled for a PhD degree in the Faculty for Mechanical Engineering, University of Maribor, Slovenia.

* Corresponding author.
} 


\section{INTRODUCTION}

Product design definitions tend to create products that fulfil at least two criteria: their main function, and their applicability. To fashion a certain design to users, the designer has to have some knowledge about the users and their properties and requirements. Such knowledge can be obtained by detailed study of known and specific populations of users who use certain products - for example, the cockpit for a Formula 1 car. The second method of gaining knowledge about users is to obtain existing information from a wide range of specific populations.

Ergonomics is an interdisciplinary science that provides information-knowledge about potential users [1]. In most cases, a designer needs information about human anatomical, anthropometric, physiological, and biomechanical characteristics and their relation to physical activity - such as working postures, materials handling, repetitive movements, work-related musculoskeletal disorders, workplace layout, safety, and health. Ergonomic studies therefore form an important phase of the product design process, and make the designer responsible for establishing the ergonomic value of the developed product [2].

Designers have to deal daily with increasing demands regarding the ergonomics of products [3]. Understandably, designers cannot perform thorough ergonomic studies of specific populations, and need some sources of pre-prepared ergonomic data. The usual sources are national or international standards (ISO, DIN, EN) or recommendations covering some specific field of ergonomic design [4].

These recommendations can contain various static or dynamic anthropometrical and biomechanical data (Figure 1), which can be used for product dimensioning.

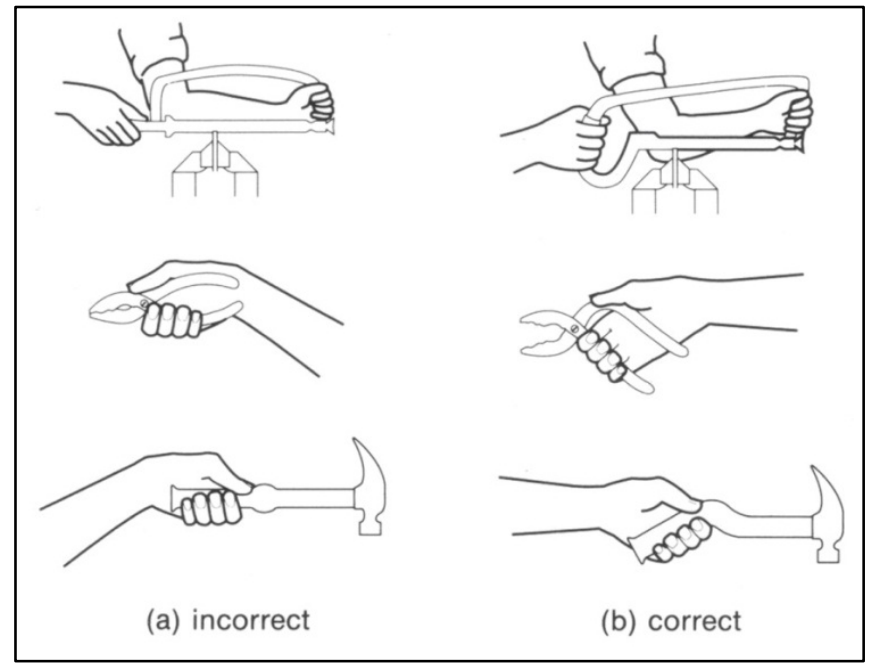

Figure 1: Recommendations for hand tool handle design [5]

To use all the information about the design of certain products correctly, the designer needs to be an expert about, and have experience in, many fields of design, including ergonomics. Such multi-level experts are hard to find and usually fully occupied.

Two alternatives are used to substitute for these experts:

- teams of experts covering all the different areas of knowledge are established; or

- intelligent computer programs with expert knowledge are applied.

Teams of experts can provide suitable design solutions - usually using special modelling and simulating techniques, such as described in [6] - but in most cases they do not provide 
concrete, partial solutions of the small details that are often needed by the designer. On the other hand, an intelligent computer program is available to the designer at any moment, and can be used in different stages of the design. In order to develop such an intelligent system, expert knowledge needs to be collected, organised, and encoded into the knowledge base of the system.

At present we are developing an intelligent advisory system called 'Oscar'. Like many other intelligent systems, Oscar is being developed to support designers. In this particular case, support is provided to deal with the aesthetic and ergonomic aspects of design. This system will consist of two sub-systems that can be applied in two different modes: either using the sub-systems independently from each other, or using them simultaneously and interdependently on the same design project [7]. The most important part of all intelligent systems is the knowledge base. It is essential, therefore, to collect and organise domain knowledge in order to build a high-quality knowledge base.

This paper presents such a knowledge acquisition process by studying a relevant product in this case, a chainsaw. Knowledge collected in this case study has been used to develop design recommendations specific to the engine-powered hand-tool group of products. The design recommendations are also briefly presented in this paper.

\section{ERGONOMIC DESIGN KNOWLEDGE ACQUISITION}

Over the last decade, the application of intelligent systems for supporting the various phases of the design process has become increasingly important [8]. The effectiveness of the system depends mainly on the quality of the knowledge base and the appropriateness of the system's inference engine.

Domain knowledge can be collected in different ways:

- by studying relevant literature and standards;

- by studying relevant projects; or

- by interviewing human experts.

The second knowledge acquisition method will be discussed in more detail.

When the knowledge has been acquired, it needs to be organised and arranged so that the inference engine of the system can access and use this knowledge effectively. To achieve this, an appropriate formalism for the knowledge representation must be chosen. In the field of design, production rules are the most commonly-used formalism for encoding knowledge, as they are quite similar to the actual rules used in the design process [9].

\section{DESCRIPTION OF PRODUCT OBSERVED}

\subsection{What is a chainsaw?}

The chainsaw was invented because of the tiring work of a traditional hand saw, and the need for faster and more effective work. It was invented to fell trees, cut and work on wood, and for other outdoor woodwork. The chainsaw currently belongs to a group of relatively heavy, high-powered portable power tools, operated by a single person.

Generally the chainsaw does with ease what humans find difficult:

- $\quad$ penetrability - this is the main feature of every saw; and

- exertion - the chainsaw is a powered hand tool that uses a motor to reduce the human workload.

The terminology for the basic parts, as used in this paper, is presented in Figure 2. Some of the data acquired during this case study originates from various producers and their models, and is presented in the models' technical portfolios. Most of the data was gained by studying the STIHL MS 361C chainsaw model. 


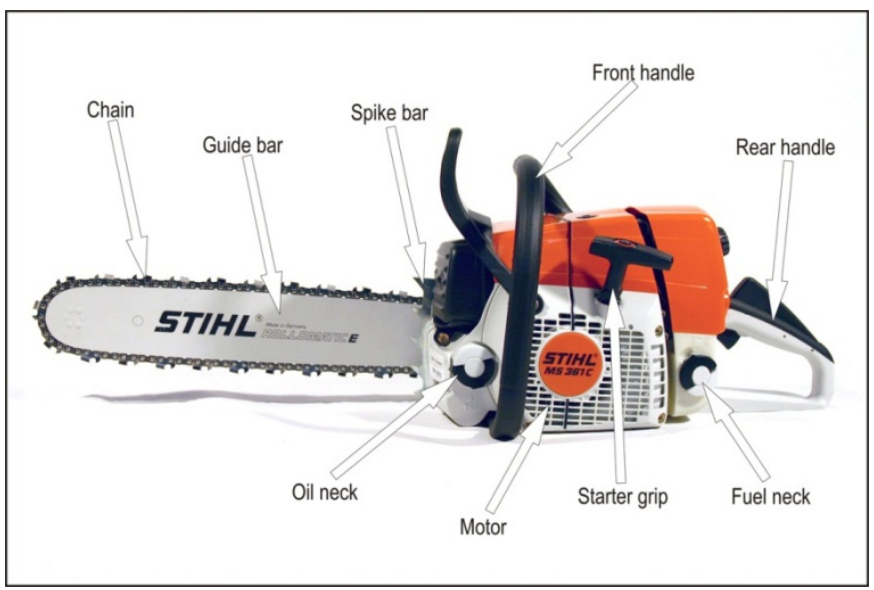

Figure 2: Terminology of basic parts [10]

The first step in this case study was to carry out an initial analysis of certain aspects of working with a chainsaw, and of some features of the chainsaw that are important from an ergonomic design point of view.

\subsection{Application characteristics}

\subsubsection{User and environment}

The chainsaw is used in outdoor environments, very often in chilly weather. Chainsaw operators - lumberjacks - are usually experienced adult men in good physical condition who are satisfied with their jobs. Use of the chainsaw by women is not usual. Operators usually wear high-quality non-slip protective gloves [11] and other protective clothing.

\subsubsection{Weight, moments of inertia, vibrations, and other forces}

The chainsaw is relatively heavy (the weight is proportional to the power of the chainsaw). The internal moving parts of the motor, and transmissions along the chain, have relatively large moments of inertia [12]. The reaction force from the cutting chain is transferred into the chainsaw during each cut. Chainsaw motors and cutting parts produce relatively high levels of vibration and noise.

\subsubsection{Movements and operating positions}

The chainsaw is used to cut wood in the following positions (needed cuts):

- vertical cuts at the level of the hips and below - most often at the level of the hips and thighs, but occasionally up to shoulder level;

- horizontal and oblique cuts to fell a tree, at the level of the calf or ankles;

- diverse cuts in horizontal, vertical, and other oblique planes, at the level of the hips and below, to trim a felled tree.

Types of movements during the work:

- individual cuts are executed by a direct movement in the cutting direction, or by wheeling the chainsaw through the cut around a chunk;

- relocating the chainsaw between individual cuts with diverse types of movements;

- individual movements can be performed by movements of the upper extremity (within the wrist, elbow, and shoulder), by movements of the upper half of the body (within the torso), by movements of the whole body (within the legs), or by a combination of these.

\section{ERGONOMIC DESIGN SOLUTIONS}

\subsection{Grips}

A safe and sure grip is needed. The power grip is the best - indeed, the only - suitable type of grip for this purpose, because the chainsaw is quite heavy, and large forces and moments 
are applied. The power grip [13] requires less human exertion to grasp the handles than any other type of grip.

Two handles are needed to split the exertion and the weight of the chainsaw during handling and operating. Two handles also provide better control over the work. For extremely heavy chainsaws, additional handles for a second operator are necessary.

\subsubsection{Front handle}

The front handle - with its horizontal, vertical, and curved transition parts - provides countless numbers of possible grasps for every position of the chainsaw without needing to bend the wrist. The horizontal part is for vertical cuts, the vertical part for horizontal cuts, and the curved part for diverse oblique cuts. Due to its formation around the chainsaw, it also ensures that the centre of gravity and the grasp points remain in the same suitable configuration. The most frequently-used horizontal part should be slightly diverted (around $100^{\circ}$ from the rear handle) in the horizontal plane (Figure 3 ) to avoid bending the wrist (to eliminate ulnar deviation). Inclining the horizontal part of the front handle in the vertical plane would be more suitable for the wrist (to eliminate pronation), but is not useful overall [14]. (This modification would bring more problems than benefits. For example, changing the axial force in the handle would bring about a disadvantageous change of the axis of rotation around this horizontal part: the change at the wrist would be from palmar or dorsal flexion to ulnar or radial deviation). Generally, we consider the design of this part to be very successful: it keeps the wrist in the best possible position in every situation. This is also why the front handle is more loaded by the weight of the chainsaw. It also offers some support, and acts as a fulcrum for rotating the chainsaw. The left arm and forearm are in the most suitable position to fulfil this function (short lever arms).

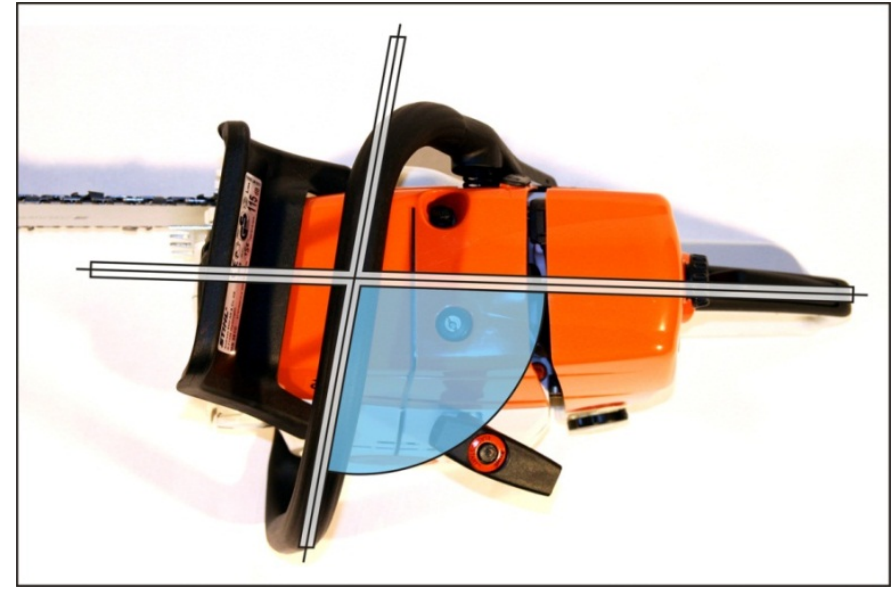

Figure 3: Inclination of the front handle

\subsubsection{Rear handle}

The rear handle is rather problematic. It is very difficult to say which angle of inclination is the best (Figure 4). A different angle is needed for different tasks to keep the wrist in a neutral position. The horizontal - or only slightly-declined - position of the handle is suitable for cutting in the horizontal position. For cutting in a vertical position (trimming), the heavily inclined handle is suitable. The solution is a compromise: a handle designed for use in all situations, even though the wrist may deviate. The compromise angle of inclination (around $25^{\circ}$ ) keeps the wrist in a neutral position when the chainsaw is used in the most common positions. The use of an adjustable handle with a variable angle of inclination is impossible because the working positions are changed very quickly and often, especially during trimming. Adjusting the handle would thus take more time than real cutting - a situation that would be inconceivable. 


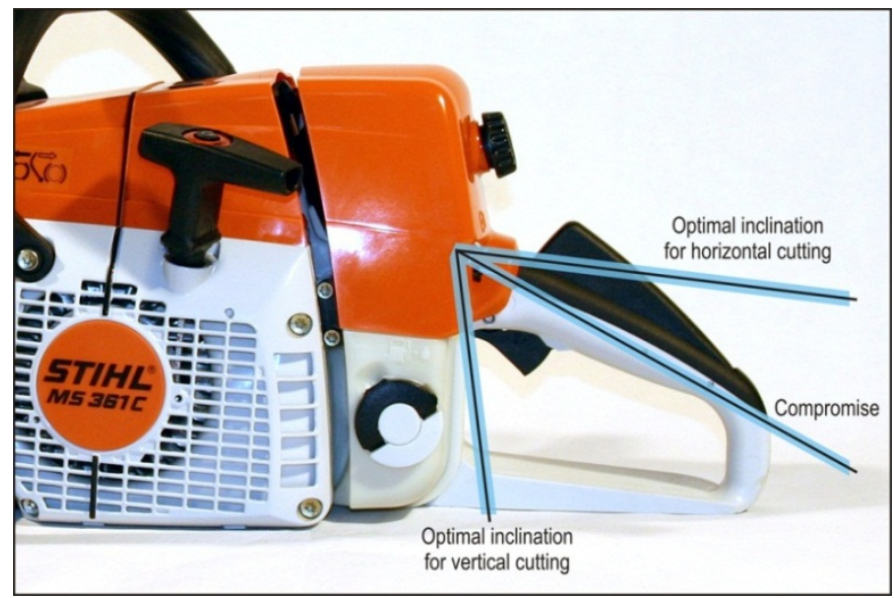

Figure 4: Inclination of the rear handle

\subsubsection{Handle positioning}

Handles placed close to the body at the level of the hips and waist decrease the lever arm within the human arm, and keep an optimal angle between the arm and forearm (Figure 5). Handles placed at opposite sides of the chainsaw, with the centre of gravity between them, ensure the shortest arm level, the easiest movements, and the least exertion during operation. The handle for the right hand should be loaded a little less. This way, the right hand does not have to grasp the handle very hard, and so can control the trigger more precisely and easily. This lighter load is better for the tendon of the index finger as it passes through the carpal tunnel in the loaded right wrist.
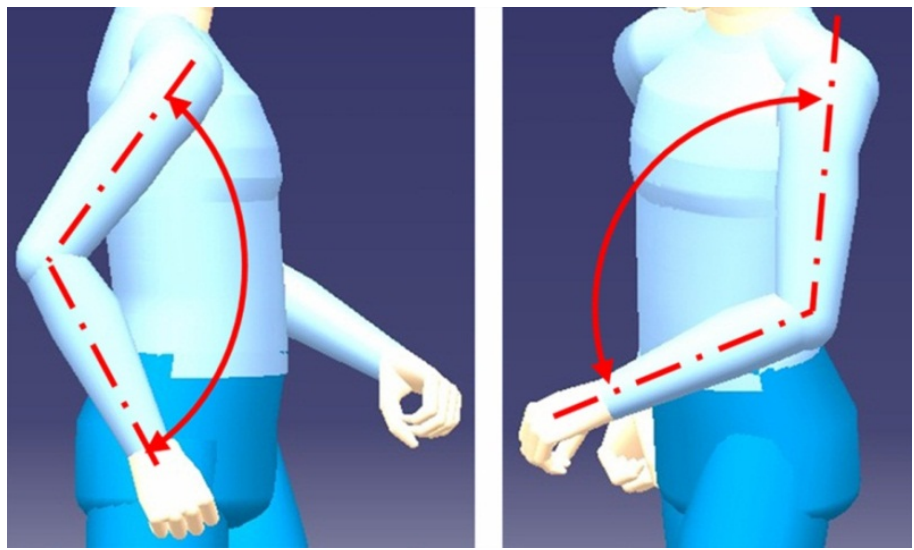

Figure 5: Position of the handles

The rear handle should be placed below the level of the front horizontal handle, somewhere on the lower half of the chainsaw. This permits rotation of the chainsaw without excessive bending (ulnar deviation) of the wrist, it maintains an optimal angle between the arm and forearm, and it keeps the elbow close to the body. Placing the rear handle on the right side of the back of the chainsaw provides more space for the hips and legs, thus keeping the chainsaw closer to the body. The right hand can also keep the same position on the handle during horizontal felling cuts, because rotation into this position is initially performed within the elbow (flexion of the forearm), and eventually with slight palmar flexion. When necessary, in extreme positions, the right hand can easily grasp the handle from the left side, pressing the trigger with the right thumb. Large and frequent ulnar and radial deviations of the right wrist are unavoidable when performing this task, but the rear handle is not loaded as much as the front handle. The most important function of the rear handle is to perform movements of the chainsaw, and not to hold large weights. 


\subsubsection{Dimensions, handle shapes (cross-sections), and material of the grips}

A round non-contoured cross-section is suitable for the front handle. It enables a number of grasps along the whole length of the handle with diverse turnings of the hand. The large radius of the curved transition part enables an easy and sure grasp at this point.

For the rear handle, an oval (elliptical) shape is suitable because the hand grasps the handle in the same position (Figure 6).

The circumference of the handles $(85-110 \mathrm{~mm})$ should guarantee the power grip, and take into account the use of thick gloves. The circumference should be larger for hobby chainsaws $(95-130 \mathrm{~mm})$ because hobby-users usually only use thin gloves, or they do not use gloves at all. The length of the rear handle should be at least $110 \mathrm{~mm}$.

The rear handle may taper slightly along its length because the ring finger and little finger are shorter. The power grip is therefore easier to use with this smaller diameter.

The front handle should be covered with rubber sheeting to avoid slippage [15], and the rubber may be knurled for better performance. The rear handle is protected with an enclosure that prevents slippage. This handle may also be knurled or dimpled. No specialised non-slip materials are needed because the use of quality leather gloves avoids slippage.

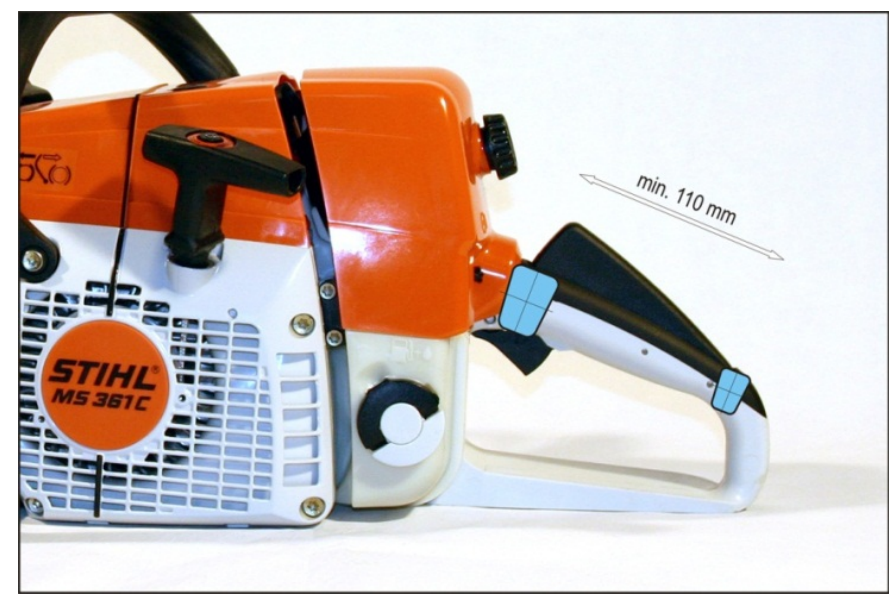

Figure 6: Dimensions of the rear handle

\subsection{Controls}

Palmar trigger lockers that do not need any additional finger movements are widely used. They have a long leverage, and only minimal force is needed to press them. Once the trigger locker is pressed, no pressure is felt on the palm.

Single finger triggers are sufficient for engine controls like the carburettors of gas engines. They do not need a large force for operating; and when the index finger operates the trigger, the other fingers grasp the handle firmly. The triggers should be wide enough (at least $5 \mathrm{~mm}$ ) [16] and rounded to spread the force (Figure 7).

Trigger locks may be used to reduce the static load when performing long cuts, but the use of these locks is debatable on the grounds of safety. 


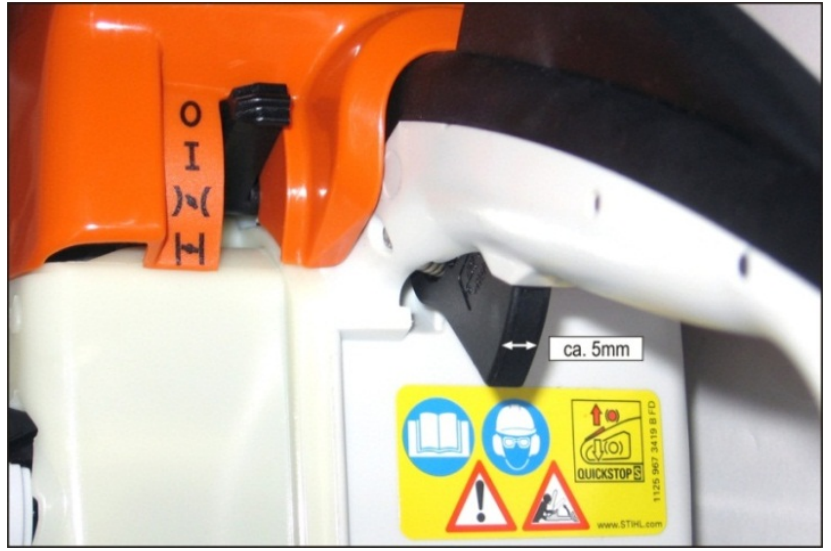

Figure 7: Dimensions of the trigger

\subsection{Vibration, noise, and cold}

Fully-separated handles attached to the engine and cutting parts with damping springs reduce vibrations below hazardous limits. Modern chainsaws commonly reach vibration levels of between 0.25 and $1.08 \mathrm{~g}$ [10]. Using quality gloves filled with damping material should reduce the level of vibration to the minimum.

The noise level of modern petrol engine chainsaws violates health and safety regulations (95-115 dB) [10]; this requires the use of hearing protectors.

Heated handles with adjustable heating output are available to keep the operator's hands warm and the blood circulating.

\subsection{Decreased exertion}

Most of the down cuts are performed using the lower part of the guide bar. Rotation of the chain (Figure 8 ) should be in such a direction that the reaction force (white arrow) pulls the chainsaw forward. This reaction force can then be caught by the spike bar (grey arrows). If the rotation were reversed, the chainsaw would be pushed towards the operator, who would have to hold this force with his arms. This configuration would also be more dangerous.

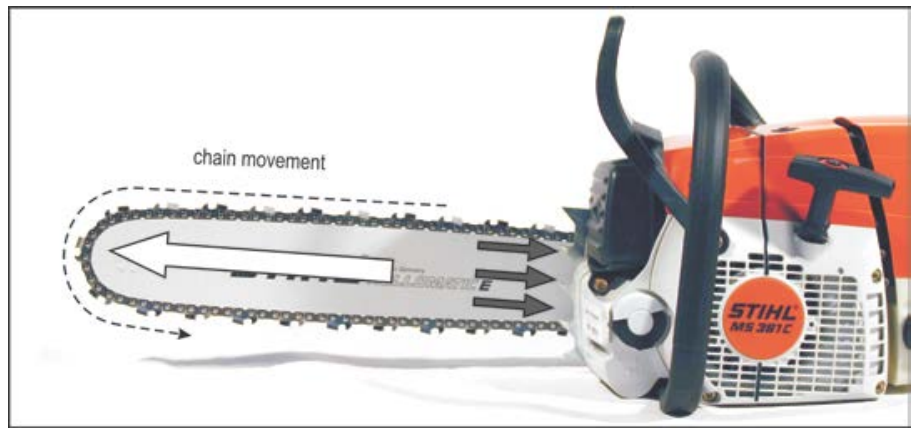

Figure 8: Forces on the chainsaw during cutting process

\subsection{Work safety}

The chainsaw is seldom the cause of cumulative trauma disorders; rather, chainsaw use is related to instant traumas. The chainsaw is extremely dangerous due to its sharp, rotating, uncovered chain. Some working positions may greatly increase this danger. The so-called kickback effect and a broken flying chain cause the most serious injuries. Special design solutions are used to prevent those situations, or to eliminate their consequences. Such design solutions are: 
- Chain brake - This acts as a protector between the left hand and the chain, especially in the hobby category. When a kickback occurs, the chain brake - pushed forward by the wrist - stops the chain in a fraction of a second.

- Chain catcher - Its main function is to catch the broken chain and prevent it from flying away.

- $\quad$ Right hand guard - It protects the right hand from a broken fly chain.

- Dead man's trigger and trigger locker - These prevent accidental activation (trigger locker), and stop the chain immediately after it is released (dead man's trigger).

- Easy and accessible safety switch - The stop button close to the right thumb can easily be used to turn off the saw at any time.

- Additional protective bar - This is a passive protective element that prevents the chain from hitting the lumberjack when kickback occurs.

- Kickback area protective cover - This protects the end of the bar from contact with the work piece.

- Compact design - The smooth streamlined design with no sharp edges prevents accidental involution of clothing or other mishaps.

\subsection{Cognitive ergonomics}

The colour red is widely used for triggers and safety switches. Blue (representing cold) is usually used for chokes. Vertical, easy-to-reach safety switches are used, with 'OFF' in the down position. Red, orange, and other colours that do not occur in the forest are used for general colouring; these make the chainsaw visible and easy to find (especially after lunch). Controls are placed on the rear handle and are operated by the right hand.

Using red for the triggers and switches and for a unit's general colouring could mask the controls; contrasting colours should be used.

\subsection{Accessories}

Fuel and oil filler necks (Figure 9) should be easily accessible, with enough space for the canister when filling. Filler neck caps should also be easy to open when using gloves. Indicators showing the level of filling (or the use of transparent tanks) enable easy control, and avoid dangerous situations (involving fuel) or damage to the chainsaw (from oil).

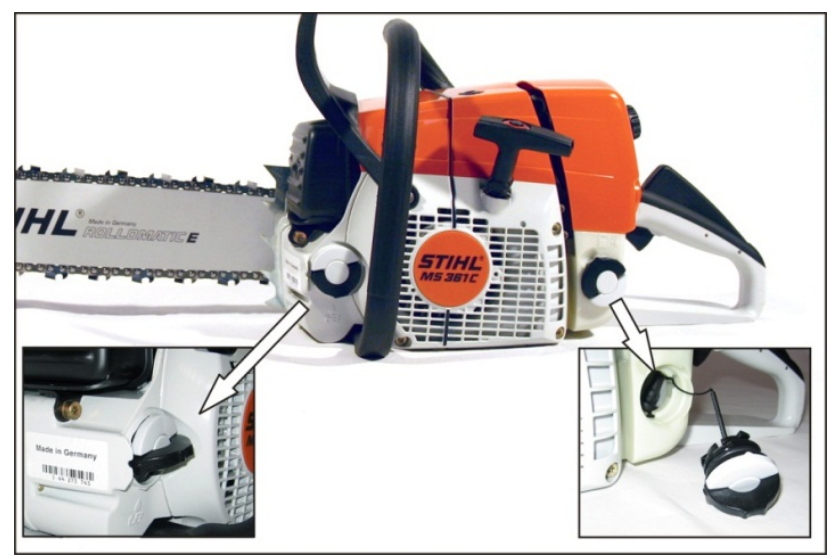

Figure 9: Accessible and easy-to-open fuel neck

Where possible, the covers (air filter, spark plug, chain replacement) should be easily removed without the use of any additional tools. Adjusting the chain strain should also be possible without additional tools.

Decompression valves may be used to decrease the lumberjack's exertion when starting the saw. Starting resistors may be used in electric chainsaws to decrease the effect of inertia 
forces, and thus avoid jerking. The starter grip should be long enough for at least three fingers (about $8 \mathrm{~cm}$ ) [17], rounded, and wide enough to spread the pulling force.

\subsection{Special ergonomic solutions}

Hydraulic and pneumatic chainsaws need a relatively large force to open the valve; full hand lever triggers are suitable for producing this required force and then spreading it. The disadvantage of this design is that when the trigger is not pressed, the power grip on the handle is lost. However, this need not be a problem, because these tools are lightweight and can easily be held one-handed, using the front handle.

Specialised chainsaws for tree surgery are designed to be as small as possible for working in treetops. The handle for the right hand is located on the top of the saw, close to the centre of gravity (Figure 10), allowing easy operation with only one hand. Generally, this configuration of handles provides a better grip when working with a raised arm or arms, or when working above the head.

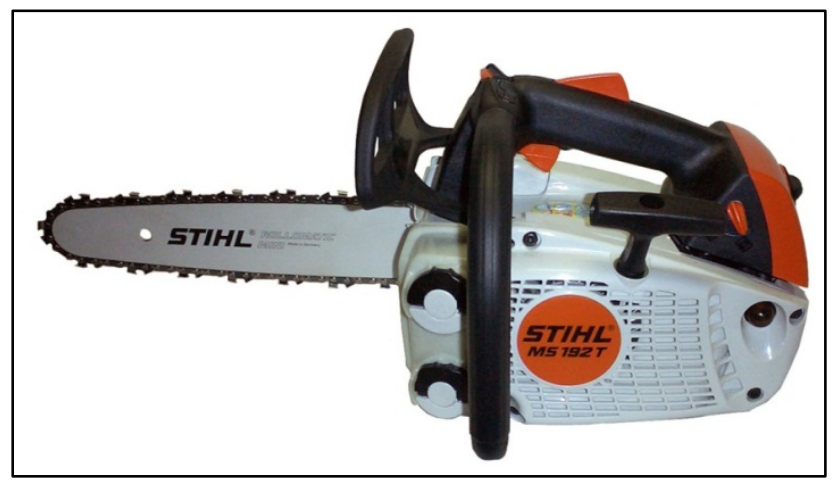

Figure 10: Tree surgery chainsaw

Hobby chainsaws, intended for cutting firewood on a sawhorse, are designed for only one working position: a front handle with a horizontal part, and the rear handle only slightly inclined. This keeps the wrist in a natural position, and only slight movements within the wrist are needed when cutting wood on the sawhorse.

A traditional thumb-trigger locker is widely used, especially on electric chainsaws. It is a good solution: the locker is placed under the thumb in its natural position within the power grip. Only a small additional force is needed to activate the locker. This type is gradually being replaced by a more comfortable palm-trigger locker.

The overall design of the chainsaw - especially its main part, the motor - defines the position of the guide bar and the saw chain. According to this configuration, the moving parts (fly wheel, saw chain, and sawdust ejection) are positioned on the right-hand side from the user's perspective. The centre of gravity is positioned under the front handle. All designs are therefore for right-handed users. A left-handed user has to adapt to this configuration, or can be provided with an additional front handle, which can be attached on the opposite side of the existing front handle to ensure an adequate position for a lefthanded user. However, using the chainsaw in this configuration is not very comfortable.

\section{DERIVED DESIGN RECOMMENDATIONS}

An important part of the knowledge acquisition process is the exact specification of the global hand tool ergonomic design goals $[4,5,18]$ that need to be followed by the designer of the hand tool to meet health, safety, and efficiency requirements.

Some of the goals that are recognised as the most important are:

- To consider the anthropometrical data to define dimensions and configurations; 
- To maintain the wrist in a neutral, straight position;

- To avoid tissue compression;

- To reduce excessive forces;

- To protect against vibration, heat, cold, and noise;

- To ensure that the task can be performed at the appropriate height;

- $\quad$ To reduce the static load;

- To ensure work safety; and

- To consider cognitive ergonomics.

The results of the case study described in this article are now presented, using a selection of the goals defined above, along with recommendations on how to execute them in the design phase.

\subsection{Maintain wrist in a neutral, straight position}

Recommendations:

- Use pistol grip for vertically-orientated grips.

- Use inline grip (cylindrical grip) for horizontally-orientated grips.

- Use deviated handles, which maintain a straight wrist.

\subsection{Avoid tissue compression}

Recommendations:

- Use handles of adequate length and thickness that span the entire hand.

- Use padding to soften the surface of the handle.

- Use contoured handles to spread the pressure over a large area.

\subsection{Reduce excessive forces}

Recommendations:

- Use power grips, and avoid the use of forceful pinch grips with straight fingers.

- Use an appropriate grip size. To generate the greatest grasping force, design grips that allow the thumb and forefinger to overlap slightly.

- Reduce resistance of tool activators (triggers, trigger lockers, etc.).

- Use alternative non-mechanical triggers (vacuum, optical, electrical, etc.).

- Increase leverage within the tool. Add more fulcrums. Extend the lever arm.

- Improve tool balance. Reduce tool length. Locate heavy masses, such as the motor and the battery, as close as possible to the wrist.

- Where a relatively large force is needed to activate the tool, use trigger levers for multiple fingers, instead of a single point trigger, to spread the activating force.

- $\quad$ Avoid sharp edges on triggers and handles.

- Add a second handle near the front end of the tool to spread exertion between the two hands.

- Increase contact friction on handles. Use non-slip, non-porous, and slightly compressible materials.

- Use a collar where the force is applied coaxially to the handle. It may reduce the grasping force.

\subsection{Protect against vibration, heat, cold, and noise}

Recommendations:

- Improve the overall tool design (taking natural frequencies into account) to decrease vibration distribution from the motor or other sources of vibration to other connected parts and handles.

- Use isolation mounts, such as springs and silent rubber blocks, between individual parts.

- Use damped tool handles.

- Use damping materials on the surface of the handle.

- Use heated handles where needed.

- Cover hot parts of the tool, such as motors. 


\subsection{Reduce the static load}

Recommendations:

- Reduce the weight of the tool.

- Improve tool balance. Reduce tool length. Locate heavy masses (motor, battery, etc.) as close as possible to the wrist.

\subsection{Work safety}

Recommendations:

- Design protective guards around moving elements.

- Design elements to prevent unwanted activation - throttle interlock.

- Ensure elements or procedures for an emergency stop.

- Design adequate guards around contact areas to prevent hand injuries.

- Design guards to prevent a broken or derailed moving element from striking the user.

\subsection{Cognitive ergonomics}

Recommendations:

- Use red for switch buttons, or for warnings and points of danger.

- Use vertical switches with the following meaning: up - 'ON', down - 'OFF'.

- Use the right hand to operate the trigger and other controls.

\section{INTELLIGENT SUPPORT OF ERGONOMIC DESIGN PROCESS}

Various advanced approaches have been investigated to improve not only the product development process, such as those reported in [19] and [20], but also the product manufacturing process [21]. The need for the integration of ergonomics into product design has been evident for quite a long time [22]. However, the need for knowledge-based decision-support within the ergonomic design process has been more recently defined. It is based on the knowledge that conventional ergonomic CAD tools do not meet the expectations of design engineers. While they offer a reasonable level of support in various ergonomic analyses [23], they fail to provide any kind of meaningful advice from an engineering point of view, in terms of design recommendations leading to better ergonomic value of the product.

In order to overcome this bottleneck and to round off the cognitive cycle [24] for the continuous improvement of a product's ergonomics, we are developing a prototype of an intelligent advisory system - Oscar - based on expert design-knowledge management.

A possible logical frame of ergonomic-knowledge management was proposed by Du et al. [25] at the Computer-Aided Industrial Design \& Conceptual Design conference in 2009. Here, the aesthetic appearance of the product was not considered an influential parameter. However, in our system, as presented in Figure 11, aesthetic appearance is considered. Oscar is made up of two sub-systems that can be applied in two different modes. We can use them independently from each other, or simultaneously and interdependently on the same design project.

\section{INTELLIGENT SYSTEM OSCAR}
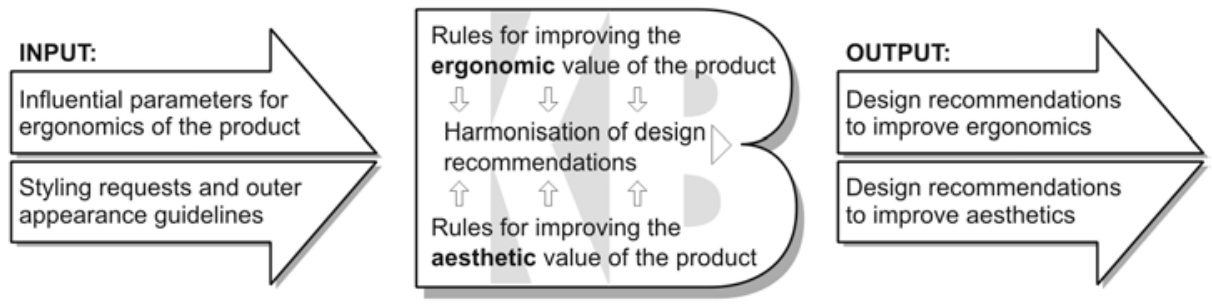

Figure 11. Basic structure of the intelligent advisory system 'Oscar' 
In the simultaneous mode, the task of the inference engine is not only to derive and propose recommendations for both ergonomic and aesthetic design improvements, but also to synchronise and harmonise possible design solutions in order to find the optimal balance between the two aspects of the product being developed.

The intelligent decision support system Oscar is still a research prototype and, as such, is subject to intensive development, especially the more subjective part of the system dealing with engineering aesthetics and aesthetic ergonomics [26]. The structure of Oscar's knowledge bases allows the inference engine to derive the necessary information (recommendations) using common procedures in expert systems such as backward chaining.

\subsection{Knowledge presentation formalism}

Different approaches to knowledge acquisition [27] and the appropriate formalisms for the presentation of acquired knowledge [28] within the computer program are of special importance. Transparent and modular 'IF-THEN' rules (also called production rules [29]) whose advantages are neutral knowledge representation, uniform structure, separation of knowledge from its processing, and the possibility of dealing with incomplete and uncertain knowledge, are considered the most suitable formalism for knowledge representation in expert systems, and are therefore chosen for presenting knowledge in the Oscar system.

Following the basic structure of the production rules, the rules dealing with ergonomic design aspects have the following form:

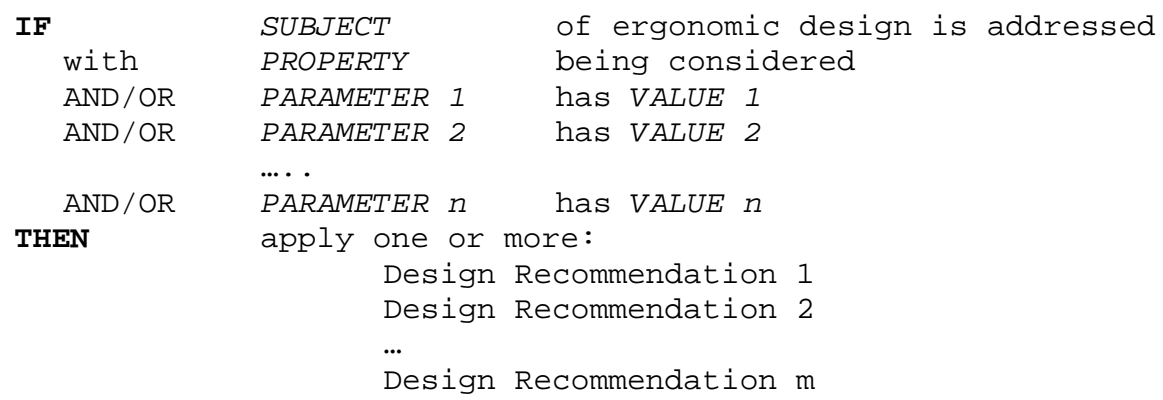

Different combinations of 'subjects', 'properties', 'parameters', and their 'values' determine different lists of ergonomic design recommendations. Table 1 shows some of the 'properties', 'parameters', and their corresponding 'values' used in production rules when the handle is the 'subject' of the ergonomic design, and the user is right-handed. Adequate recommendations are also presented in Table 1. The knowledge base also contains knowledge regarding the design of the handle where the user is left-handed (same structure as presented). To fit both groups of users, a 'third group' of knowledge is provided.

Considering the data presented in Table 1 and the ergonomic design recommendations discussed in the previous section, we can construct the actual rules. Here, for example, is a simple rule for the type and position of the front handle:

IF

(handle, cross-section)

AND (dimension, gloves)

THEN

AND (two_handles, rear_handle)

circumference: $85-110 \mathrm{~mm}$

type: power grip

shape: round

shape: oval 
Table 1: Some ergonomic facts for grips and possible values (for right-handed user)

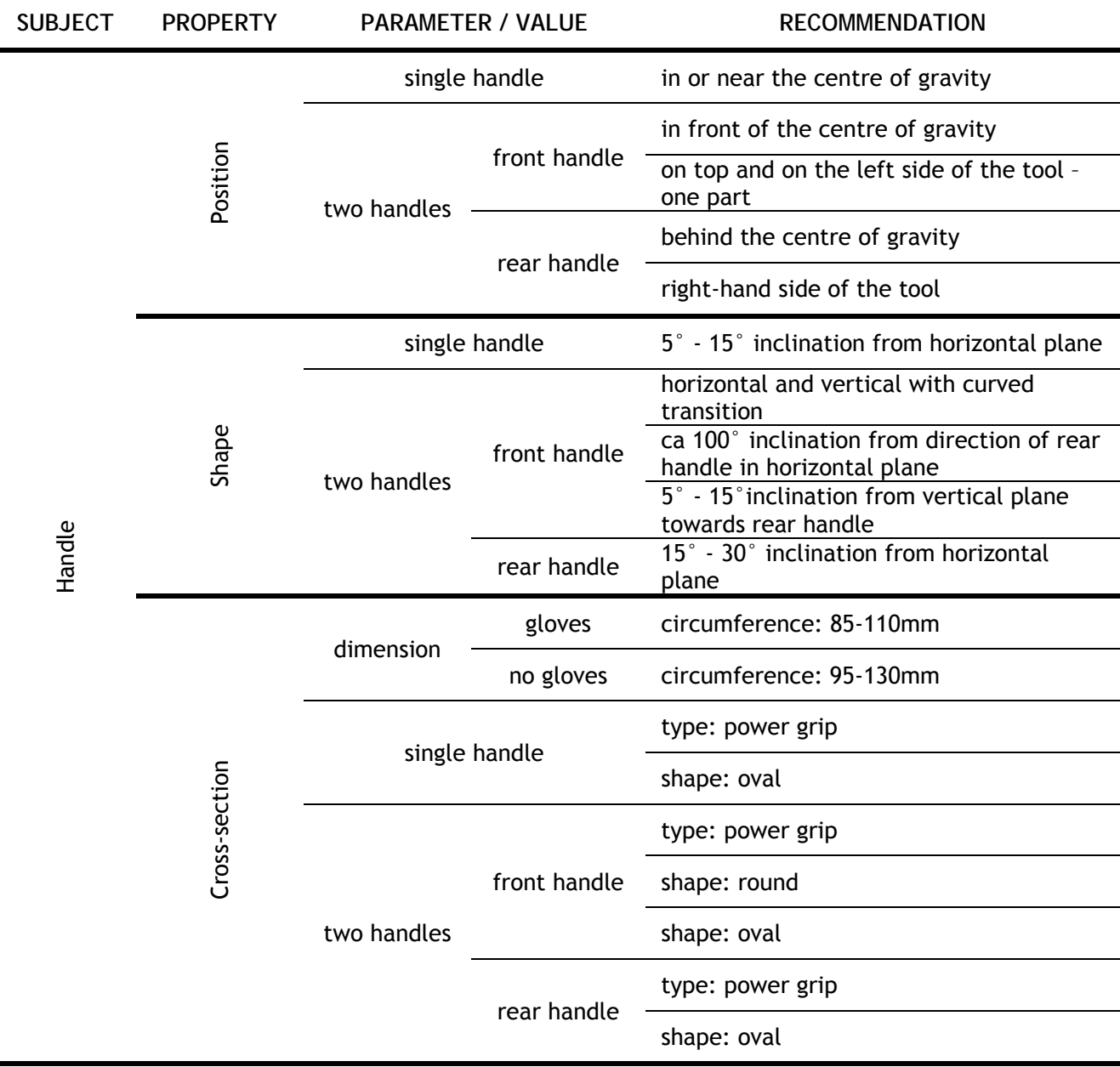

\section{CONCLUSIONS}

Ergonomics is used to improve the relationship between tool and human operator. The field of ergonomics is boundless and never-ending. The principles of ergonomics are applied today to every human activity. The theory, principles, and recommendations mentioned in this paper are only the basic ones, as they relate to hand tool design.

During this case study of the chainsaw we have determined that, in general, today's ergonomic design of the chainsaw can be considered highly successful. In relation to cumulative trauma disorders, the chainsaw seems to present few problems. (The biggest problem, that of vibration, was satisfactorily solved in the 1960s.) Use of the chainsaw is not limited to only one stereotypical posture: various postures and movements are used during the work, thus avoiding strain on a few muscles. Improvements have been made, especially to hobby chainsaws, where some mistakes have occurred. The general design of chainsaws has not changed for many years, because there has been no need to do so. In future, designers will probably focus on lowering their weight, reducing emissions, decreasing the level of noise, and improving safety elements. 


\section{REFERENCES}

[1] Burns, C.M., Vicente, K.J., Christoffersen, K. and Pawlak, W.S. 1997. Towards viable, useful, and usable human factors design guidance. Appl. Ergon, 28(5), 311-322.

[2] Butters, L.M. and Dixon, R.T. 1998. Ergonomics in consumer product evaluation: An evolving process. Appl. Ergon. 29(1), 55-58.

[3] Polajnar, A., Leber, M. and Vujica-Herzog, N. 2010. Muscular-skeletal diseases require scientifically designed sewing workstations. Strojniški vestnik - Journal of Mechanical Engineering, 56(1), 31-40.

[4] Lange W. 1993. Kleine ergonomische Datensammlung. $6^{\text {th }}$ ed., Verlag TÜV Rheinland.

[5] Dul, J. and Weerdmeester, B.A. 1998. Ergonomics for beginners: A quick reference guide. Taylor \& Francis.

[6] Lovrec, D. and Kastrevc, M. 2011. Modelling and simulating a controlled press-brake supply system. Int. J ournal of Simulation Modelling, 10(3), 133-144.

[7] Kaljun, J. and Dolšak, B. 2006. Computer-aided intelligent support to aesthetic and ergonomic design. WSEAS Transactions on Information Science and Applications, 3(2), 315-321.

[8] Gero, J.S. and Sudweeks, F. 1998. Artificial intelligence in design. Kluwer Academic Publishers.

[9] Luger, G.F. and Stubblefield, W.A. 1989. Artificial intelligence and the design of expert systems. The Benjamin/Cummings Publishing Company, Inc., Redwood City, USA

[10] Stihl. 2006. Stihl MS 361 C professional chainsaw portfolio. ANDREAS STIHL AG \& Co. KG.

[11] Chen, Y., Cochran, D.J., Bishu, R.R. and Riley, M.W. 1989. Glove size and material effects on task perfomance. Proceedings of the $33^{\text {rd }}$ Annual Meeting of the Human Factors Society, 708-712.

[12] Armstrong, T.J., Bir, C., Foulke, J., Martin, B., Finsen, L. and Sjřgaard, G. 1999. Muscle responses to simulated torque reactions of hand-held power tools. Ergonomics 42, 146-159.

[13] Bobjer, O., J ohansson S.-E. and Piguet, S. 1999. Friction between hands and handle. Effects of oil and lard on textured and non-textured surfaces; perception and discomfort. Appl. Ergon. 24(3), 190-202.

[14] Muggleton, J.M., Allen, R. and Chappell, P.H. 1999. Hand and arm injuries associated with repetitive manual work in industry: A review of disorders, risk factors and preventive measures. Ergonomics, 42, 714-739.

[15] Fellows, G.L. and Frievalds, A. 1991. Ergonomics evaluation of a foam rubber grip for tool handles. Appl. Ergon. 22, 225-230.

[16] Kroemer, K., Kroemer, H. and Kroemer-Elbert, K. 2000. Ergonomics - how to design for ease and efficiency, $2^{\text {nd }}$ ed. Prentice Hall.

[17] Cacha, C.A. 1999. Ergonomics and safety in hand tool design. Lewis Publishers.

[18] Noyes, J.M. 2001. Designing for humans. Hove Press.

[19] Brunetti, G. and Golob, B. 2000. A feature-based approach towards an integrated product model including conceptual design information. Computer-Aided Design, 32, 877-887.

[20] Kremljak, Z., Polajnar, A. and Buchmeister, B. 2005. A heuristic model for the development of production capabilities. Stroj niški vestnik - J ournal of Mechanical Engineering, 51(11), 674-691.

[21] Hachicha, W. 2011. A simulation metamodelling based neural networks for lot-sizing problem in MTO sector. Int. J ournal of Simulation Modelling, 10(4), 191-203.

[22] Nagamachi, M. 1995. Kansei engineering: A new ergonomic consumer oriented technology for product development. International J ournal of Industrial Ergonomics, 15, 13-24.

[23] Butters, L.M. and Dixon, R.T. 1998. Ergonomics in consumer product evaluation: An evolving process. Applied Ergonomics, 29(1), 55-58.

[24] Gielingh, W. 2008. Cognitive product development: A method for continuous improvement of products and processes. Stroj niški vestnik - J ournal of Mechanical Engineering, 54(6), 385-397.

[25] Du, S., Wu, Q., Wang, Y. and Yi, Z. 2009. Study of method for computer-aided ergonomics knowledge management and design aiming at product design. Computer-Aided Industrial Design \& Conceptual Design, 1176-1180.

[26] Liu, Y. 2003. Engineering aesthetics and aesthetic ergonomics: Theoretical foundations and a dual-process research methodology. Ergonomics, 46(13/14), 1273-1292.

[27] McMahon, C., Lowe, A. and Culley, S. 2004. Knowledge management in engineering design: Personalization and codification. J ournal of Engineering Design, 15, 307-325.

[28] Valls, A., Batet, M. and Lopez, E.M. 2009. Using expert's rules as background knowledge in the ClusDM methodology. European J ournal of Operational Research, 195, 864-875.

[29] Bratko, I. 1990. Prolog programming for artificial intelligence, $2^{\text {nd }}$ ed. Wokingham: AddisonWesley. 